\title{
Cervical tuberculous lymphadenitis
}

\author{
Chong Karleen, ${ }^{1}$ Jeyasakthy Saniasiaya (1) ${ }^{2}$
}

'Department of Primary Care Medicine, University of Malaya, Kuala Lumpur, WP Kuala Lumpur, Malaysia

${ }^{2}$ Department of

Otorhinolaryngology, Faculty of Medicine, University of Malaya, Kuala Lumpur, W P Kuala Lumpur, Malaysia

\section{Correspondence to} Dr Jeyasakthy Saniasiaya; shakthy_18@yahoo.com

Accepted 28 April 2021

Check for updates

(C) BMJ Publishing Group Limited 2021. No commercial re-use. See rights and permissions. Published by BMJ.

To cite: Karleen $C$ Saniasiaya J. BMJ Case Rep 2021;14:e241807. doi:10.1136/bcr-2021241807

\section{DESCRIPTION}

A previously healthy 26-year-old man presented with 1-month history of right-sided neck swelling. According to him, the swelling progressively increased in size over 1 week and concurrently became red and painful. There was no dysphagia or odynophagia. He denied recent fever, upper respiratory infection, B-symptoms or constitutional symptoms. He had no recent sick contact, travelling and or any pets or animal contact. Additionally, patient denies high-risk behaviour, and he is a nonsmoker. The patient visited multiple clinics for the past month, completed two courses of antibiotics, however, the neck swelling persists.

On examination, the patient was afebrile, not septic looking and was comfortable under room air. Neck examination revealed right supraclavicular swelling measuring $5 \times 6 \mathrm{~cm}$, fluctuant with no visible punctum, tender and erythematous looking (figure 1). Additionally, multiple matted, firm, non-tender lymph nodes were appreciated corresponding to level II of right side of the neck. No other lymph nodes or hepatosplenomegaly were palpable. Lung auscultation was clear and equal bilaterally. Complete baseline blood investigations performed were unremarkable, however, erythrocyte sedimentation rate (ESR) was raised; $53 \mathrm{~mm} /$ hour.

Fine-needle aspiration done under local analgesia yielded frank pus which was sent for culture and sensitivity (C\&S) along with acid-fast bacilli (AFB). The pus AFB sent showed presence of AFB (figure 2), hence a diagnosis of tuberculous lymphadenitis was made and the patient was referred to the respiratory department for a full tuberculosis (TB) workup and anti-TB was commenced. Mantoux test performed was positive; $17 \mathrm{~mm}$ with unremarkable chest radiography as well as sputum AFB.

Neck mass, although a common presentation to the primary care clinic remains a conundrum ensuing the multitude possibility. With an exhaustive list of differential diagnoses, ranging from benign to serious etiologies, all physicians should equip themselves with knowledge of common neck masses. This is to facilitate them in managing the condition or to refer to the otorhinolaryngology or surgical department for further investigations and treatment.

The most common form of extrapulmonary $\mathrm{TB}$ is tuberculous lymphadenitis or scrofula, especially in the cervical region. ${ }^{12}$ This condition is commonly caused by Mycobacterium tuberculosis although atypical mycobacterium such as $\mathrm{Myco}$ bacterium avium and Mycobacterium kansasii, has been reported in the literature, especially involving children. Interestingly, five stages involving the

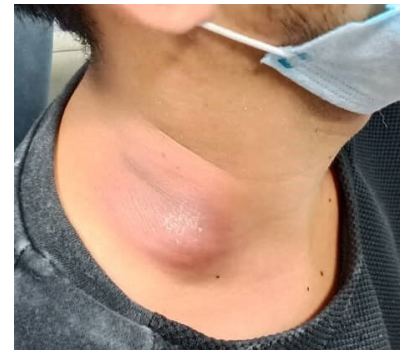

Figure 1 Right erythematous supraclavicular swelling.

progression of tuberculous lymphadenitis has been described by Jones and Campbell ${ }^{3}$ (box 1). Our patient presented in stage 3, where there was abscess formation.

Most patients with cervical tuberculous lymphadenitis do not present with systemic symptoms, ${ }^{14}$ similar to our patient. Patients with bacterial lymphadenopathy habitually presents with constitutional symptoms of malaise, fever and loss of weight and generally respond to appropriate antibiotics. B-symptoms are commonly seen among lymphoma patients, whereas metastatic head and neck carcinoma patients presents with associated skin lesions or ear, nose or throat symptoms. Kikuchi disease also known as histiocytic necrotising lymphadenitis typically presents with painless cervical lymphadenopathy with or without systemic signs and symptoms. It is a self-limiting, autoimmune condition with a female predominance and is managed through supportive treatment.

Assessment of cervical masses has been recently accompanied by fine-needle aspiration cytology (FNAC) owing to its high sensitivity and specificity as a reliable diagnostic tool. For countries like Malaysia, where TB cases are discovered on a day-to-day basis, granulomatous changes in combination with caseous or coagulative necrosis are highly suggestive of tuberculosis. ${ }^{5}$ It is imperative that Ziehl-Neelsen (ZN) staining for AFB should be carried out together with mycobacterium C\&S as negative $\mathrm{ZN}$ staining does not rule of TB and mycobacterium C\&S can be positive which prompts a repeat of FNAC or even a tissue biopsy. $^{6}$

Myriad protocol regime exists to date to manage extrapulmonary TB. In our practice, 6-month combination chemotherapy of rifampicin, isoniazid, pyrazinamide and ethambutol is implied. Chemotherapy was proven to be effective in comparison to surgical excision of the involved lymph nodes. Prior to initiation of chemotherapy, a host of investigations should be carried out, including complete blood count, ESR, renal profile, liver function test, viral screening, sputum AFB direct smear, Mantoux test and chest X-ray as in our patient. 
Box 1 Stages of progression of tuberculous

lymphadenitis

Jones and Campbell classification

1. Stage 1: enlarged, firm, mobile, discrete nodes showing nonspecific reactive hyperplasia.

2. Stage 2: large rubbery nodes fixed to surrounding tissue owing to periadenitis.

3. Stage 3: central softening due to abscess formation.

4. Stage 4: collar-stud abscess formation.

5. Stage 5: sinus tract formation.

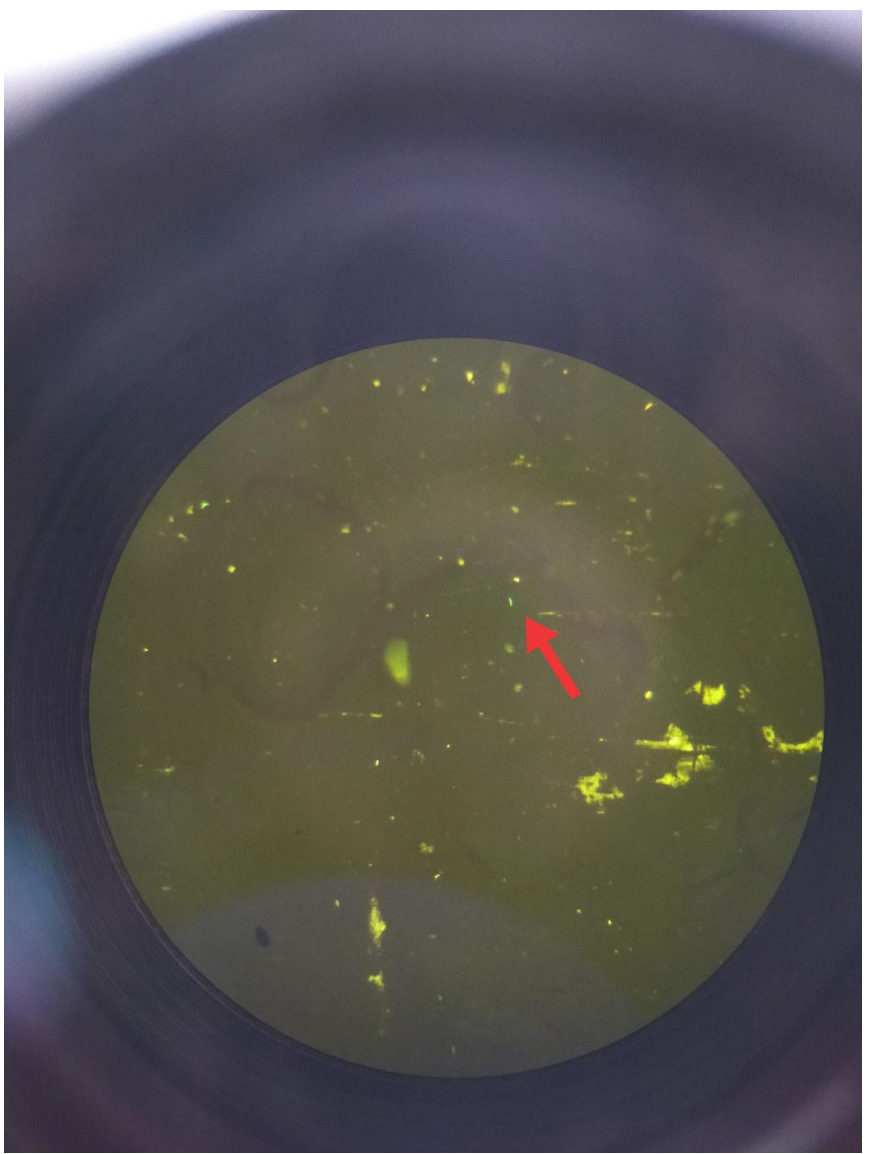

Figure 2 Presence of acid-fast bacili. Arrow: acid-fast bacilli
Challenge in managing cervical tuberculous lymphadenitis is that there is no clear guide for assessment of extrapulmonary TB following treatment. Additionally, postcompletion of treatment, residual lymph node can be observed in nearly $15 \%-30 \%$ of patients. Residual lymph node may not necessarily indicate treatment failure and may be following a paradoxical reaction. Hence, close monitoring of the lymph node is crucial on weather microbiological testing is needed following a short-term observation.

Prognosis of cervical TB lymphadenitis is good provided patient is compliant to the chemotherapy regimen and follow-up. Having said so, it is prudent that resistance towards antituberculous medication, which is burgeoning rapidly, is discovered early and managed to ensure fatal ramifications are avoided.

\section{Learning points}

- The presence of fluctuant neck mass in an adult patient requires thorough investigations, including tuberculosis (TB) screening along with viral screening for HIV.

- Simple bedside aspiration may lead to the diagnosis of TB lymphadenitis thus avoiding complications such as poor wound healing from incision and drainage.

- If TB lymphadenitis is suspected and acid-fast bacilli smear is negative, histopathological examination for TB PCR should be sent.

Contributors CK: conceptualisation, drafting. JS: editing, final approval.

Funding The authors have not declared a specific grant for this research from any funding agency in the public, commercial or not-for-profit sectors.

Competing interests None declared.

Patient consent for publication Obtained.

Provenance and peer review Not commissioned; externally peer reviewed.

ORCID iD

Jeyasakthy Saniasiaya http://orcid.org/0000-0003-1974-4379

\section{REFERENCES}

1 Jha BC, Dass A, Nagarkar NM, et al. Cervical tuberculous lymphadenopathy: changing clinical pattern and concepts in management. Postgrad Med J 2001;77:185-7.

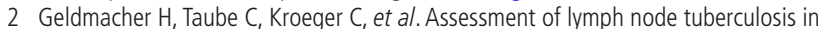
northern Germany: a clinical review. Chest 2002;121:1177-82.

3 Jones PG, Campbell PE. Tuberculous lymphadenitis in childhood: the significance of anonymous mycobacteria. Br J Surg 1962;50:302-14.

4 Yao M, Zhu Z-H, Lian N-F, et al. Treatment for 15 cases of cervical tuberculosis. Chin Med J 2017;130:1751-2

5 Handa U, Mundi I, Mohan S. Nodal tuberculosis revisited: a review. J Infect Dev Ctries 2012;6:6-12

6 Seok $\mathrm{H}$, Jeon JH, Oh KH, et al. Characteristics of residual lymph nodes after six months of antituberculous therapy in HIV-negative individuals with cervical tuberculous lymphadenitis. BMC Infect Dis 2019;19:867.

Copyright 2021 BMJ Publishing Group. All rights reserved. For permission to reuse any of this content visit https://www.bmj.com/company/products-services/rights-and-licensing/permissions/

BMJ Case Report Fellows may re-use this article for personal use and teaching without any further permission.

Become a Fellow of BMJ Case Reports today and you can:

- Submit as many cases as you like

- Enjoy fast sympathetic peer review and rapid publication of accepted articles

- Access all the published articles

- Re-use any of the published material for personal use and teaching without further permission

Customer Service

If you have any further queries about your subscription, please contact our customer services team on +44 (0) 2071111105 or via email at support@bmj.com.

Visit casereports.bmj.com for more articles like this and to become a Fellow 